\title{
Typical Loads of Concrete Beams Strengthened with FRP Sheet
}

\author{
Wang Feng ${ }^{1,2, a, *}$, Zhang Jian ${ }^{3, b}$, Ye Xin ${ }^{4, c}$ and Jiang Lei ${ }^{3, d}$ \\ ${ }^{1}$ Institute of Bridge Engineering, Tongji University, Shanghai, China \\ ${ }^{2}$ Jiangsu Yangtze River Bridge Co., Ltd., Nanjing, China \\ ${ }^{3}$ Nanjing University of Aeronautics and Astronautics, Nanjing, China \\ ${ }^{4}$ Southeast University ChengXian College, Nanjing, China \\ a wangfjydq@163.com, ${ }^{\mathrm{b}}$ jianzhang78@126.com, c yexinseu@126.com, ${ }^{\mathrm{d}}$ leijnuaa@163.com \\ *Wang Feng
}

Keywords: FRP sheets, concrete beam, typical loads.

\begin{abstract}
The reinforced technology by using FRP sheet has a certain application in practical engineering, it basically adopts the passive paste of non prestressed FRP sheet to raise the bearing capacity of components. Carbon fibre has high tensile strength and modulus of elasticity, but the ductility of the carbon fibre is poor. Relative to the carbon fibres, glass fibre plays a complementary role. It is a new reinforcement technique to reinforced concrete beams by prestressed FRP. Based on the theory of hierarchical units, a calculation model of reinforced concrete beam is established for the prestressed strengthened beams in FRP. The overall dates of the concrete beam under loads at three dividing point are analyzed. Comparative analysis of yield load, ultimate load, deformation and ductility performance has been worked out. Typical loads of concrete beams strengthened with FRP fibre sheets are analyzed in detail in this paper.
\end{abstract}

\section{Introduction}

Two fibre by hybrid together can show better than the single fibre in mechanical properties, and its properties is not a simple superposition of a single material[1-2]. The reasons are as follows. When using two kinds of blended fibre, high extensibility fibre can afford additional load which is caused by low extensibility fibre fracture, and increase the average fracture strain of the hybrid fibre[3-4]. Using two kinds of blended fibre can delay the failure process of from micro to macro. And the fibres which low ductility which crack still can be in the form of short fibres with high ductility of the fibre to work together until all fibre fracture in succession[5-7]. In order to meet the specific needs in different project, the ratio of the fibre can be adjusted to improve the force performance[8-9]. This paper establishes a nonlinear mechanics model of concrete beam reinforced with prestressed C/GFRP fibre to calculate the reinforced structure and the optimal hybrid C/GFRP ratio is achieved through the systematic calculation based on two main properties which take the strength and ductility properties into consideration. Typical loads of concrete beams strengthened with C/GFRP fibre sheets are analyzed in detail in this paper.

\section{Mechanical Model of Concrete beams strengthened with FRP Fibre Sheet}

Concrete beams strengthened with C/GFRP fibre sheets are simulated by entity degradation element. The midsection has nine controlling nodes in Figure 1, which is used to describe the degradation element of information about the corresponding element decreased significantly. Concrete, stirrups and structural reinforcement in the concrete beams can take concrete layer element to simulate. For vertical reinforced (main), using layer element simulating is too approximate, this paper uses composition element to simulate concrete beams. The displacement of 9 nodes degradation element is as follows:

$$
\boldsymbol{\delta}_{i}=\left[\begin{array}{lllll}
u_{i} & v_{i} & w_{i} & \beta_{1 i} & \beta_{2 i}
\end{array}\right]^{T}
$$




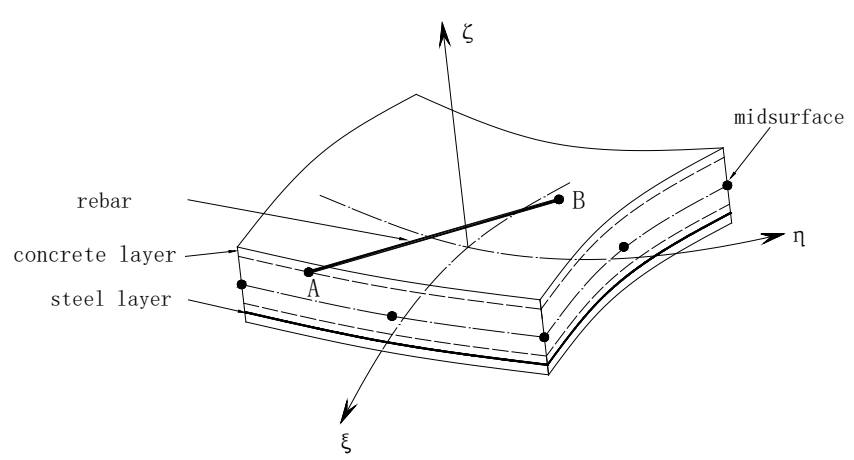

Figure 1 Combined shell element with rebar.

Where $\left[u_{i} v_{i} w_{i}\right]$ is the line displacement of the node $i$ in the overall system, $\left[\beta_{1 i} \beta_{2 i}\right]$ is the angle displacement of the $i$ node in the node coordinates. Displacement field by interpolation can be expressed as the shape function:

$$
\begin{aligned}
& u=\sum_{i=1}^{n} N_{i} u_{i}+\sum_{i=1}^{n} N_{i} \frac{h_{i}}{2} \zeta\left(v_{1 i}^{x} \beta_{1 i}-v_{2 i}^{x} \beta_{2 i}\right) \\
& v=\sum_{i=1}^{n} N_{i} v_{i}+\sum_{i=1}^{n} N_{i} \frac{h_{i}}{2} \zeta\left(v_{1 i}^{y} \beta_{1 i}-v_{2 i}^{y} \beta_{2 i}\right) \\
& w=\sum_{i=1}^{n} N_{i} w_{i}+\sum_{i=1}^{n} N_{i} \frac{h_{i}}{2} \zeta\left(v_{1 i}^{z} \beta_{1 i}-v_{2 i}^{z} \beta_{2 i}\right)
\end{aligned}
$$

Where $N_{i}$ is the shape function of node $i, h_{i}$ is the element thickness of node $i, v_{1 i}^{x}$ is a cosine between the node coordinate $\mathbf{v}_{1}$ and the overall system $\mathrm{x}$ of node $i$ (the same to others). The main reinforcement in the combination element in concrete beams starts with point $\mathrm{A}$ and ends with point B. Therefore, this article does not consider the interface bond-slip effect, the hybrid fibre sheet element with concrete beam element use the node processing.

\section{FRP Materials Model}

It is assumed that the C/GFRP fibre sheet and concrete have good bonding properties. And C/GFRP fibre sheet is anisotropic and cannot bear the pressure and bending moment of the material, and it can only bear the longitudinal strain. Thus the C/GFRP fibre sheet is perfectly elastic before breaking. According to the test, the ultimate strength of C/GFRP fibre sheet is 2956.3MPa, the C/GFRP fibre sheet disappears completely when the strength of CFRP/GFRP fibre sheet is 2956.3MPa. The Owen triaxial yielding criterion and Hinton crush model are utilized.

\section{Nonlinear Convergence Criteria}

The displacement convergence criterion is adopted:

$$
\frac{\left\|\boldsymbol{\delta}_{i+1}-\boldsymbol{\delta}_{i}\right\|_{2}}{\left\|\boldsymbol{\delta}_{i+1}\right\|_{2}}<\varepsilon
$$

Where $\boldsymbol{\delta}_{i}$ is the convergent solution of the incremental step $i$ of the solution of nonlinear equations, which is the value of the whole displacement vector of the C/GFRP fibre strengthened concrete beam in step increment $i . \boldsymbol{\delta}_{i+1}$ is the convergent solution of the incremental step $i+1$ of the solution of nonlinear equations. The value $2.5 \%$ is treated as the convergence tolerance $\varepsilon$

\section{Analysis of the Example}

The size of prestressed C/GFRP fibre reinforced concrete beam in Figure2 is $150 \mathrm{~mm} \times 250 \mathrm{~mm} \times 250 \mathrm{~mm}$, longitudinal reinforcement is 2 क 14, stirrup is $\phi 8 @ 150$, symmetrical reinforcement, the thickness of protective layer is $25 \mathrm{~mm}$. The thickness of fibre sheet is $0.23 \mathrm{~mm}$. 
According to the different ratio of C/GFRP hybrid fibre performance by composite material production elements, and after comprehensive comparison, seven kinds of hybrid fibre are chosen as a theoretical analysis in Table 1 to find the optimal mixture ratio, which is based on both strength and ductility index calculation analysis of prestressed C/GFRP fibre sheet. For convenient, carbon fibre can be abbreviated to C, carbon-glass 1:1 can be abbreviated to CG11, carbon-glass 1:2 can be abbreviated to CG12, carbon-glass 1:3 can be abbreviated to CG13, carbon-glass 2:1 can be abbreviated to CG21, carbon-glass 3:1 can be abbreviated to CG31, glass fibre can be abbreviated to G. Nonlinear combination element and shell element are adopted to establish the calculation model of C/GFRP fibre reinforced concrete beam. The model has 120 elements and 533 nodes, and the prestressed C/GFRP fibre sheet shell element is 20, the rest is the concrete beam element. Each load point is loaded as $3 \mathrm{kN}$ in the whole process of analysis.
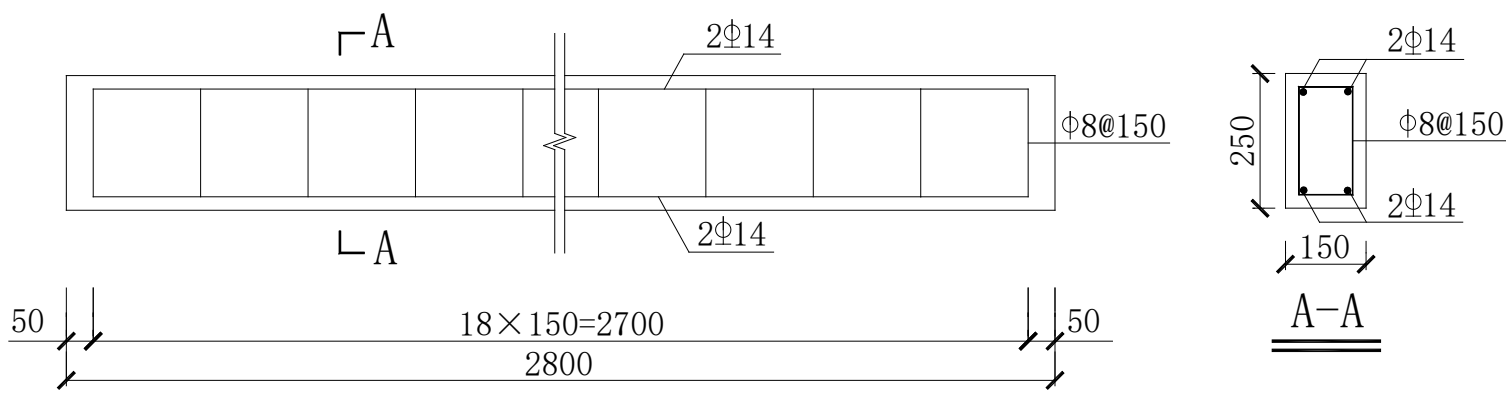

Figure 2 Dimensions of the studied concrete beam/mm.

The optimal mixture ratio is studied in the whole process of calculation about prestressed C/GFRP fibre reinforced concrete beams, concrete strength level is C25, fibre sheet prestressed degree is $0-0.4$, The crack load and yield load, ultimate load and the load level at the time of the prestressed C/GFRP fibre sheet, midspan deflection of beam body development data have extracted through the process in Table 2 where PD means prestress degree, CL means crack load, CD means crack deformation, YL means yield load, YD means yield deformation, UL means ultimate load, UD means ultimate deformation and DY means ductility.

Table 1 Performance of hybrid CFRP/GFRP fibre with different ratio

\begin{tabular}{cccc}
\hline Symbol & $\begin{array}{c}\text { Tensile } \\
\text { Strength/MPa }\end{array}$ & $\begin{array}{c}\text { Tensile } \\
\text { Modulus/MPa }\end{array}$ & $\begin{array}{c}\text { Ductility } \\
(\%)\end{array}$ \\
\hline C & 3848 & 234200 & 1.6 \\
CG11 & 2838 & 171260 & 2.0 \\
CG12 & 2349 & 124088 & 2.2 \\
CG13 & 2161 & 90012 & 2.4 \\
CG21 & 3063 & 190963 & 1.8 \\
CG31 & 3266 & 207213 & 1.7 \\
G & 2003 & 75021 & 2.7 \\
\hline
\end{tabular}


Table 2 Typical loads of beams strengthened with prestressed C/GFRP sheet

\begin{tabular}{|c|c|c|c|c|c|c|c|c|}
\hline PD & FRP & $\begin{array}{l}\text { CL/ } \\
\mathrm{kN}\end{array}$ & $\begin{array}{l}\mathrm{CD} / \\
\mathrm{mm}\end{array}$ & $\begin{array}{l}\text { YL/ } \\
\mathrm{kN}\end{array}$ & $\begin{array}{l}\mathrm{YD} / \\
\mathrm{mm}\end{array}$ & $\begin{array}{l}\mathrm{UL} / \\
\mathrm{kN}\end{array}$ & $\begin{array}{l}\mathrm{UD} / \\
\mathrm{mm}\end{array}$ & DY \\
\hline \multirow{7}{*}{0} & C & 6.00 & 0.82 & 48.0 & 9.45 & 76.5 & 37.70 & 3.99 \\
\hline & CG11 & 6.00 & 0.83 & 48.0 & 10.12 & 75.0 & 52.10 & 5.15 \\
\hline & CG12 & 6.00 & 0.84 & 42.0 & 8.47 & 70.5 & 49.70 & 5.86 \\
\hline & CG13 & 6.00 & 0.85 & 42.0 & 8.63 & 66.0 & 52.62 & 6.10 \\
\hline & CG21 & 6.00 & 0.83 & 48.0 & 9.88 & 69.0 & 35.97 & 3.64 \\
\hline & CG31 & 6.00 & 0.82 & 48.0 & 9.58 & 76.5 & 42.37 & 4.42 \\
\hline & $\mathrm{G}$ & 6.00 & 0.86 & 42.0 & 8.70 & 66.0 & 50.46 & 5.80 \\
\hline \multirow{7}{*}{0.2} & $\mathrm{C}$ & 12.00 & 0.62 & 54.0 & 8.91 & 82.5 & 34.26 & 3.84 \\
\hline & CG11 & 12.00 & 0.94 & 54.0 & 10.00 & 75.0 & 36.72 & 3.67 \\
\hline & CG12 & 12.00 & 1.10 & 48.0 & 8.72 & 70.5 & 38.02 & 4.36 \\
\hline & CG13 & 12.00 & 1.20 & 48.0 & 9.00 & 67.5 & 41.94 & 4.66 \\
\hline & CG21 & 12.00 & 0.86 & 54.0 & 9.62 & 79.5 & 39.92 & 4.15 \\
\hline & CG31 & 12.00 & 0.78 & 54.0 & 9.35 & 79.5 & 37.48 & 4.01 \\
\hline & G & 12.00 & 1.27 & 48.0 & 9.17 & 66.0 & 44.55 & 4.86 \\
\hline \multirow{7}{*}{0.4} & $\mathrm{C}$ & 24.00 & 1.38 & 63.0 & 9.17 & 87.0 & 30.95 & 3.37 \\
\hline & CG11 & 18.00 & 1.04 & 60.0 & 9.95 & 82.5 & 40.88 & 4.11 \\
\hline & CG12 & 18.00 & 1.36 & 54.0 & 8.99 & 79.5 & 52.58 & 5.85 \\
\hline & CG13 & 12.00 & 0.53 & 54.0 & 9.39 & 72.0 & 39.27 & 4.18 \\
\hline & CG21 & 18.00 & 0.90 & 60.0 & 9.42 & 84.0 & 36.54 & 3.88 \\
\hline & CG31 & 18.00 & 0.81 & 60.0 & 9.11 & 87.0 & 38.10 & 4.18 \\
\hline & $\mathrm{G}$ & 12.00 & 0.61 & 54.0 & 9.84 & 70.5 & 42.84 & 4.35 \\
\hline
\end{tabular}

In Table 2, the strength and ductility index evaluation C/GFRP optimal mix ratio, extraction cracking load, yield load and ultimate load are listed. Due to limited space, three cases 0, 0.2 and 0.4 data is listed as follows. With comparison of different hybrid ratio, the strength index and ductility indexes of beams strengthened with CG11 are both elevated, thus CG11 is the optimal hybrid form.

\section{Conclusion}

Typical value of load strengthened with prestressed CFRP sheets have improved, compared with the hybrid fibre cracking load which increase a little while the residual strength caused by the excessive waste and the ductility index both decline. Therefore, the hybrid with CFRP and GFRP sheet can give full play to their respective advantages. With comparison of different hybrid ratio, the strength index and ductility indexes of beams strengthened with CG11 are both elevated, thus CG11 is the optimal hybrid form.

\section{References}

[1] Khaled M. S., John B. K. (2002) Literature review in analysis of box-girder bridges, J. Bridge Eng., 7, 134-143.

[2] Xiang H. F. (2001) Advanced theory of Bridge structure. Beijing: The Peoples' Communications Press.

[3] Xiao R. C. (2002) Analysis of bridge structure and program system. Beijing: The Peoples' Communications Press.

[4] Ghani R. A., Hangang U. (1991) Single cell multicell box-girder finite element. Structure Engineering. ASCE, 117(10): 2953-2971. 
[5] Zhao Z. M., Chen B C. (1997) Analysis of pole system and box girder bridge and program designing. Guangzhou: Huanan University of Science and Engineering Press.

[6] Zhang Y. Q. (1978) Finite strip analysis of box girder bridge. Beijing: The Peoples' Communications Press.

[7] Shu S. H. (2003) Parameter stochastic back analysis method and object oriented programming design. Master Dissertation, Nanjing: Hohai University.

[8] Fan M. Y., Zhang Y. (1982) Basis of optimization technology. Beijing: Tsinghua University Press.

[9] Zhang J., Ye J. S., Wang C.Q. (2008) Dynamic Bayesian estimation of displacement parameters of continuous thin-walled straight box with segregating slab based on CG method, Chinese J. Comp. Mech., 25, 574-580. 